\title{
EPIDEMIOLOGICAL INVESTIGATION OF PASTEURELLA MULTOCIDA INFECTION IN POULTRY IN GAZIPUR DISTRICT OF BANGLADESH
}

\author{
M. R. Hossain ${ }^{1}$, M. M. Meher ${ }^{1 *}$ and M. Afrin ${ }^{2}$ \\ ${ }^{1}$ Department of Microbiology and Public Health, Faculty of Animal Science and Veterinary Medicine, Patuakhali \\ Science and Technology University, Patuakhali, Bangladesh; ${ }^{2}$ Department of Anatomy and Histology, Faculty of \\ Veterinary Science, Bangladesh Agricultural University, Mymensingh-2202, Bangladesh.
}

\begin{abstract}
The present study was undertaken to determine the present status of fowl cholera (FC) infection of poultry in Gazipur district during September 2016 to February 2017. A total of 282 either dead or sick birds (Layer and Sonali) were taken as sample in which the sick birds were subjected to record clinical data and consequently the dead birds were for post mortem examination. Hence, overall $12.41 \%$ prevalence was found for FC and about $87.59 \%$ was for mixed other diseases. All the birds were grouped into six named as A1, A2 and up to A6 accordingly their age. The highest incidence $(29.79 \%)$ was found in A1 (8-20weeks) group and the lowest was 4.26\% in A5 (51-60 weeks) group. Furthermore, six FC infected farms were categorized to treat with six specific antibiotics individually. Thereafter, the highest recovery rate $(89.6 \%$ and $87.5 \%)$ was recorded in two farms using Enrofloxacin and Gentamicin particularly. The lowest recovery rate $(60 \%)$ was in Erythromycin treatment group. However, the layer birds of six farms lost their body weight almost $11.84 \%$, specifically the highest percentages (16.49\%) was in treated with Ampicillin and lowest percentages $(5.79 \%)$ found in a farm treated with Gentamicin. In brief, FC commonly appears just near to laying age and therapeutic management trivially decreases the body weight that ultimately shoots up the production cost.
\end{abstract}

Keywords: Epidemiology, Pasteurella multocida, poultry, Gazipur

\section{INTRODUCTION}

Fowl cholera (FC) is considered to be one of the most contagious and economically important bacterial diseases of poultry particularly chicken, turkeys, ducks and geese caused by Pasteurella multocida and remains an important havoc for the poultry production in Bangladesh (Rimler and Glisson, 1997; Singh et al., 2014). It occurs all over the Bangladesh mostly in fall winter and late summer with $25 \%$ to $35 \%$ mortality in chickens and ducks (Ievy et al., 2013). The laying flocks are mostly affected as compared to younger chickens (Choudhury et al., 1985).

Pasteurella multocida is one of the members of Pasteurellaceae family which is coccobacillary in shape having capsule (Akhtar, 2013; Ievy et al., 2013). In addition, its capsule carries different types of polysaccharides for which it is grouped into A, B, D, E and F. Afterwards, it is further classified into 16 serotypes (1 to 16) primarily based on lipopolysaccharide antigens among them only two or three are present in Bangladesh (Choudhury et al. 1985; Kwaga et al.2013). However, Pasteurella multocida inhabits as commensal of the respiratory tract of many avian species and produces disease when the birds are under stress (Harper et al., 2006). Subsequently it is extensively involved in respiratory syndrome of commercial layers all over the world particularly in countries having hot humid environment. Fowl cholera is characterized by nasal discharge, facial edema, blackening of comb and wattles, ataxia, back ward retraction of head, rise in temperature, off feed and water, dull, depressed with high morbidity (up to 50\%) (Shah et al., 2008). This study was performed to determine the prevalence of FC in layer and Sonali in certain Gazipur district with the effect of antibiotics therapy.

\section{MATERIALS AND METHODS}

This study was conducted at Gazipur district to determine the FC infection during the period from September 2016 to February 2017. A total of 282 either dead or sick birds were subjected as sample which was from various poultry farms in different area of Gazipur district. The FC was diagnosed according to the history of the flock, age of affected birds, clinical signs and lastly post mortem lesions. All the bird's samples were grouped into 6 according to age which are named as A1 (8-20weeks), A2 (21-30

*Corresponding e-mail address: mienur@pstu.ac.bd 


\section{R. Hossain and others}

weeks), A3 (31-40 weeks), A4 (41-50 weeks), A5 (51-60 weeks), A6 ( $\geq 61$ weeks). Besides this, a total of 9350 birds of six layer farms were under close observation and the farms were named as F1, F2, F3, F4, F5 and F6. All the instruments were sterilized before postmortem examination. Separate set of instruments were used for each case. Normal saline solution $(0.9 \% \mathrm{NaCl})$ was used for cleaning tissues/organs. $10 \%$ neutral buffered formalin (4\% formaldehyde) and $70 \%$ alcohol were used for wetting and disinfecting the feathers and skin.

The birds were observed to detect clinical signs by usual inspection. All of the sick birds were examined closely by using different methods such as palpation, auscultation, percussion, needle puncture and locomotion of the birds to observe the signs. The weight of each experimental bird was measured regularly. Besides this, body temperature, pulse and respiratory rate of sick birds were also recorded. The clinical data was collected on a preformed questionnaire by close method from the farmers and person who are exclusively related with the affected flock. Each owner was asked about previous vaccination history of his/her birds suffering from FC.

The postmortem examination was performed as early as possible and not exceed to 12 hours after death Samad (2000). Most of the postmortem examinations were performed at morning hours, so there was little chance to exceed the time limit that is 12 hours. Gross pathological changes were recorded carefully with a specific consideration to define cases.

Descriptive analysis was done to express the results in percentage. Data were structured in the Microsoft ${ }^{\circledR}$ Excel spreadsheet and the percentages of disease conditions prevalent in different groups and seasons were intended.

\section{RESULTS AND DISCUSSION}

In this study, a total of 282 birds were examined among which 35 birds (Table 1) were detected as FC infection. The common clinical signs were nasal and ocular discharge, darkened head and combs, greenish watery diarrhoea, ruffled feathers, increased respiratory rate, swollen wattles, high temperatures and lameness which agreed with the findings of Khan et al. (1997) and Rahman et al. (2004).

Table 1. Prevalence of Fowl cholera in different birds at Upazilla Veterinary Hospital, Gazipur Sadar, Gazipur

\begin{tabular}{cccc}
\hline Bird Type & Total Birds & Diseased Bird No. & Other diseases \\
\hline Layer & 202 & $26(12.87 \%)$ & $176(87.13 \%)$ \\
Sonali & 80 & $9(11.25 \%)$ & $67(89.34 \%)$ \\
\hline Total & 282 & $35(12.41 \%)$ & $247(87.59 \%)$ \\
\hline
\end{tabular}

In this study, the prevalence was a little bit different from the value reported in the earlier studies. The overall prevalence of Fowl cholera was $12.41 \%$ in Gazipur Sadar. Though disease prevalence of Sonali were found $11.25 \%$ and more was (12.87\%) in layer, Belal (2013); Hasan et al. (2010) and Hossain et al. (2013) reported that the overall prevalence of FC was $11.42 \%$ in Gazipur and Sirajgonj districts. Besides, Hasan et al. (2010) found $12.05 \%$ prevalence in layer and $4.25 \%$ in broiler chicken in Mymensingh and Gazipur districts which were very much close to our study, whereas Hossain et al. (2013) found 13.04\% prevalence in in Mymensingh district in chicken and Belal (2013) found 59.72\% in backyard poultry in Sirajgonj district. In our study area, about $87.59 \%$ was mixed with other diseases which were mainly coli-enteritis, Newcastle disease, infectious coryza, coccidiosis and egg displacement etc.

Table 2. Incidence of fowl cholera in different aged bird groups at Gazipur sadar

\begin{tabular}{cccc}
\hline Age Group & Suspected Birds & Diseased Birds & Percentages Affected \\
\hline A1 & 47 & 14 & 29.79 \\
A2 & 47 & 8 & 17.03 \\
A3 & 47 & 5 & 10.64 \\
A4 & 47 & 3 & 6.38 \\
A5 & 47 & 2 & 4.26 \\
A6 & 47 & 3 & 6.38 \\
\hline Total & 282 & 35 & 12.41 \\
\hline
\end{tabular}




\section{Epidemiological investigation of Pasteurella multocida infection in poultry}

This study indicated that A1 age group was the highest (29.79\%) and A5 was the lowest susceptible (4.26\%) age group (Table 2) whereas A2 was recorded as the $2^{\text {nd }}$ highest susceptible (17.03\%) age group. Mbuthia et al. (2008) stated that 12-week-old family chickens were more susceptible. Moreover, Rimler and Glisson (1997) and Christiansen et al. (1992) reported that the infected birds remain carriers up to 9 weeks after infection which can affect birds of any age rarely less than 8 weeks of age. The prevalence of FC infection is due to improper vaccination and through interaction with those domestic birds not vaccinated for this disease.

The postmortem findings were found as cloudy air sacs, petechial hemorrhages on serosal membranes, focal necrosis on liver (Figure 1) with viscous fluid in proventriculus and intestine. There was fragile liver (Figure 2), enlarged spleen (Figure 3), congested lungs (Figure 5) and often yolk peritonitis (Figure 4.) also found. All the postmortem findings were similar to Mehmood et al. (2016) and Shivachandra et al. (2004).

Table 3. Effective antibiotics against fowl cholera

\begin{tabular}{lcccccc}
\hline Antibiotics & Farm & $\begin{array}{c}\text { Population } \\
\text { size }\end{array}$ & $\begin{array}{c}\text { Duration } \\
\text { of treatment }\end{array}$ & $\begin{array}{c}\text { Affected } \\
\text { birds }\end{array}$ & $\begin{array}{c}\text { Recovered } \\
\text { birds }\end{array}$ & $\begin{array}{c}\text { Average } \\
\text { recovery day }\end{array}$ \\
\hline Erythromycin & F1 & 1000 & 5 days & 50 & $30(60 \%)$ & $5-7$ \\
Gentamicin & F2 & 1200 & 5 days & 80 & $70(87.5 \%)$ & $5-7$ \\
Oxytetracycline & F3 & 1500 & 5 days & 40 & $32(80 \%)$ & $5-7$ \\
Doxycycline & F4 & 2000 & 5 days & 75 & $50((71 \%)$ & $5-7$ \\
Enrofloxacin & F5 & 1450 & 5 days & 48 & $43(89.6 \%)$ & $5-7$ \\
Ampicillin & F6 & 2200 & 5 days & 80 & $50(62 \%)$ & $5-7$ \\
\hline
\end{tabular}

After postmortem examination and clinical inspection, it was detected that a total of 373 birds were suffering from Fowl Cholera infection in the respective farm (Table 3). The farms were categorized into six and in which six specific antibiotics were used separately. Thereafter, the findings revealed that F5 and F2 groups had highest recovery rate $(89.6 \%$ and $87.5 \%)$ which was treated with Enrofloxacin and Gentamycin respectively. These findings are closely associated with the report of Shivachandra et al. (2004) found 71.54\% sensitivity to enrofloxacin and Hassan et al. (2017) found 100\% sensitivity to Enrofloxacin and Gentamicin in water fowl. However, the lowest recovery rate was $60 \%$ in F1 group which was treated with Erythromycin.

Table 4. Application of antibiotics and body weight (BW) gain

\begin{tabular}{lccccccc}
\hline \multicolumn{1}{c}{ Antibiotics } & Farm & $\begin{array}{c}\text { No. of } \\
\text { Birds }\end{array}$ & $\begin{array}{c}\text { Age } \\
\text { (Weeks) }\end{array}$ & $\begin{array}{c}\text { Average BW prior } \\
\text { to infection(gm) }\end{array}$ & $\begin{array}{c}\text { Average BW after } \\
\text { treatment(gm) }\end{array}$ & $\begin{array}{c}\text { Average BW } \\
\text { loss }\end{array}$ & $\begin{array}{c}\text { BW loss } \\
(\mathrm{gm})\end{array}$ \\
\hline Erythromycin & F1 & 1000 & 22 & 1824 & 1620 & 204 & 11.18 \\
Gentamicin & F2 & 1200 & 25 & 1727 & 1627 & 100 & 5.79 \\
Oxytetracycline & F3 & 1500 & 30 & 1834 & 1595 & 239 & 13.03 \\
Doxycycline & F4 & 2000 & 35 & 1789 & 1553 & 236 & 13.19 \\
Enrofloxacin & F5 & 1450 & 30 & 1786 & 1590 & 196 & 10.97 \\
Ampicillin & F6 & 2200 & 37 & 1843 & 1539 & 304 & 16.49 \\
\hline & Total & & & 10803 & 9524 & 1279 & 11.84 \\
\hline
\end{tabular}

Table 4 showed that the layer birds of six farms lost their body weight almost $11.84 \%$ due to Fowl cholera. The highest percentages (16.49\%) of body weight loss were found in F6 farm which was treated with Ampicillin and the lowest percentages $(5.79 \%)$ of body weight loss occurred in F2 which was treated with Gentamicin. Choudhury et al. (1985) reported that about 10-30\% production reduced with losses of body weight of Layer birds associated with FC which is compatible with the present study.

Fowl cholera is also a threat for poultry industry especially small scale farming in Bangladesh. It commonly appears just near to laying age and ultimately declines the body weight. However, this study will help to make a conception about the prevalence and effective treatment with specific antibiotics against FC. It's true that this is very preliminary work and in future this would require the isolation and molecular characterization with antibiogram study of avian type Pasteurella multocida with large sample size. 


\section{R. Hossain and others}

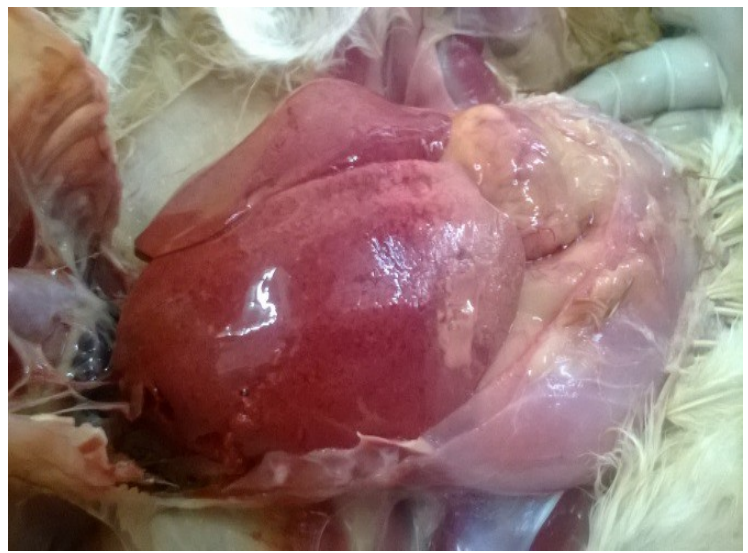

Figure 1. Necrotic foci on liver

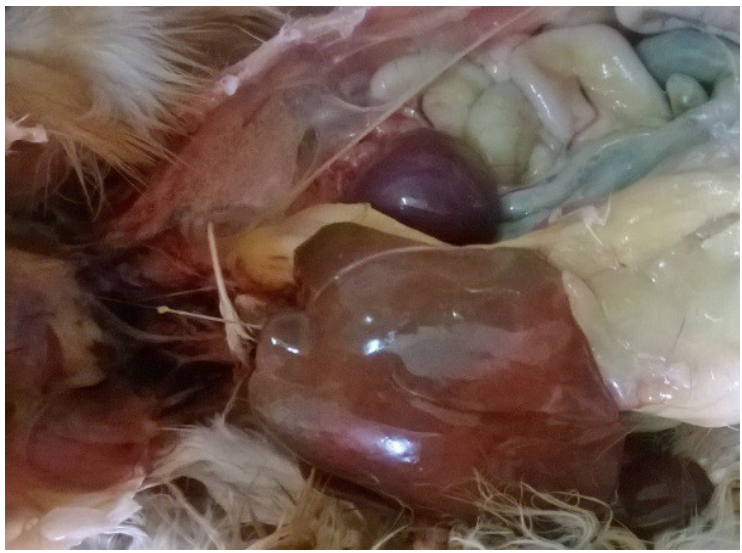

Figure 3. Enlargement of spleen

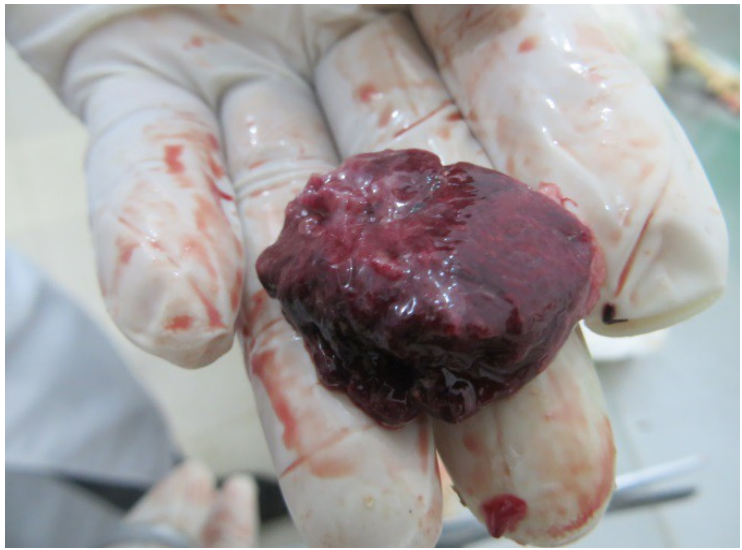

Figure 5. Congested lung

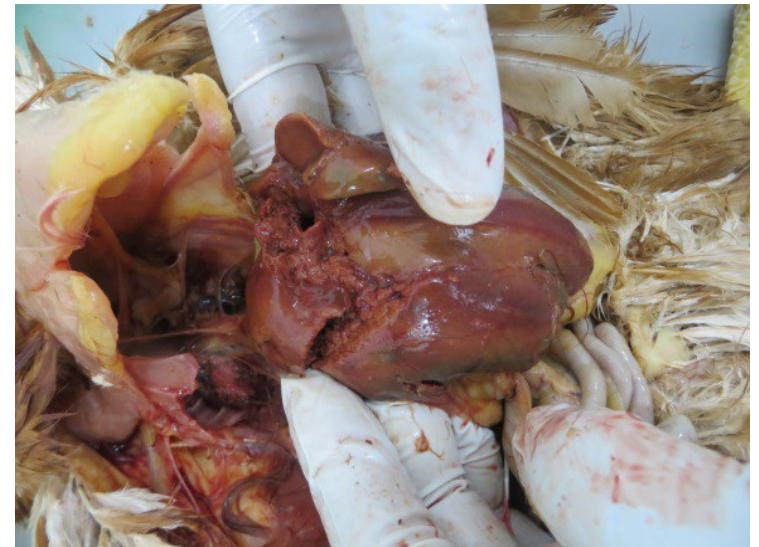

Figure 2. Fragile liver

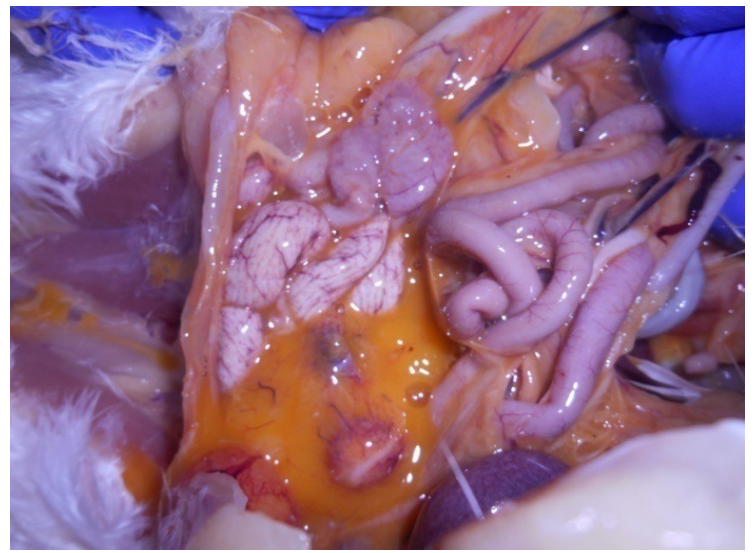

Figure 4. Unabsorbed yolk sac

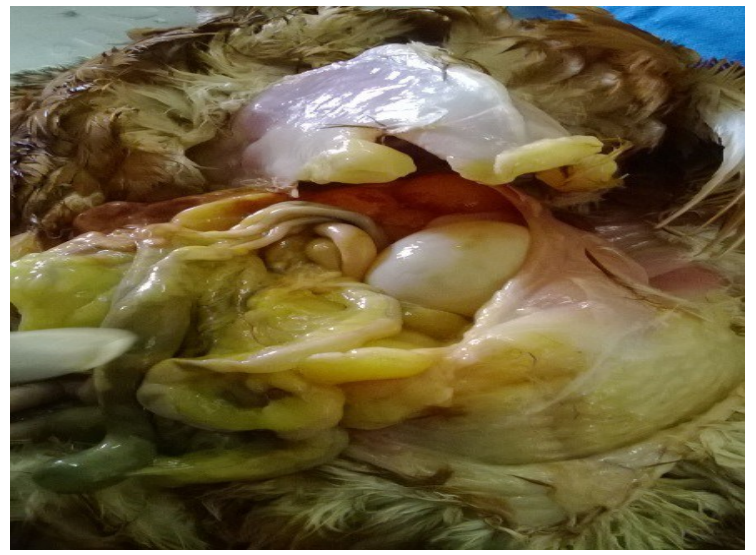

Figure 6. Greenish color feces 


\section{REFERENCES}

Epidemiological investigation of Pasteurella multocida infection in poultry

1. Akhtar M (2013). Isolation, identification and characterization of Pasteurella multocida from chicken and development of oil based vaccine, MS thesis, Department of Microbiology and Hygiene, Bangladesh Agricultural University, Mymensingh.

2. Ashraf A, Tariq H, Shah S, Nadeem S, Manzoor I, Ali S, Ijaz A, Gailani S and Mehboob S (2011). Characterization of Pasteurella multocida strains isolated from cattle and buffaloes in Karachi, Pakistan. African Journal of Microbiology Research 5: 4673- 4677.

3. Belal SMSH (2013). Occurrence of Pasturellosis and Newcastle disease in indigenous chicken in Sirajgonj district. Bangladesh Journal of Veterinary Medicine 11: 97-105.

4. Choudhury KA, Amin MR, Rahman A and Ali MR (1985). Investigation of natural outbreak of fowl cholera. Bangladesh Veterinary Journal 19: 49-56.

5. Christiansen KH, Carpenter TE, Snipes KP and Hird DW (1992). Transmission of Pasteurella multocida on California turkey premises in 1988 - 89. Avian Diseases 36: 262-271.

6. Harper M, Boyce JD and Adler B (2006). Pasteurella multocida pathogenesis: 125 years after Pasteur. FEMS Microbiology Letters 265: 1-10.

7. Hasan RAKM, Ali MH, Siddique MP, Rahman MM and Islam MA (2010). Clinical and laboratory diagnosis of broiler and layer chickens. Bangladesh Veterinary Journal 8: 107-115.

8. Hassan N, Hamadani H and Zargar UR (2017). Rare outbreak of fowl cholera in water fowls in Dal Lake area of Kashmir, with isolation, antibiogram and successful treatment. International Journal of Current Microbiology and Applied Sciences 6: 481-484

9. Hossain MS, Akter S, Ali M, Das PM and Hossain MM (2013). Bacteriological and pathological Investigation of nasal passage infections of chickens (Gallus gallus). The Agriculturist 11: 47-55.

10. Ievy S, Khan MRF, Islam MA and Rahman MB (2013). Isolation and identification of Pasteurella multocida from chicken for the preparation of oil adjuvanted vaccine. Bangladesh Journal of Veterinary Medicine 2: 1-4.

11. Khan M, Das PM, Choudhury KA and Islam MR (1997). Pathology of experimentally induced fowl cholera in chickens. Bangladesh Veterinary Journal 31: 28-34.

12. Kwaga JKP, Ekundayo SO, Chuku A, Yusuf AF, Mwankon ES, Boss SS and Muhammad M (2013). Phenotypic and genotypic characterization of Pasteurella multocida isolated from dead poultry in Jos, Plateau State. Nigerian Veterinary Journal 34: 765-774.

13. Mbuthia PG, Njagi LW, Nyaga PN, Bebora LC, Minga U, Kamundia J and Olsen JE (2008). Pasteurella multocida in scavenging family chickens and ducks: carrier status, age susceptibility and transmission between species. Avian Pathology 37: 51-57.

14. Mehmood MD, Qazi MH, Muhammad K, Shahid M, Akram M, Amin F, Gul M and Ali MA (2016). Isolation and molecular characterization of Pasteurella multocida from commercial layer flocks suffering from respiratory syndromes. The Journal of Animal and Plant Sciences 26: 304-308.

15. Rahman MA, Samad MA, Rahman MB and Kabir SML (2004). In vitro antibiotic sensitivity and therapeutic efficacy of experimental salmonellosis, colibacillosis and pasteurellosis in broiler chickens. Bangladesh Journal of Veterinary Medicine 2: 99-102.

16. Ranjan R, Panda SK, Acharya AP, Singh AP and Gupt AMK (2011). Molecular diagnosis of haemorrhagic septicaemia. Veterinary World 4: 189-192.

17. Rimler RB and Glisson JR (1997). Diseases of poultry. 10 ${ }^{\text {th }}$ ed., Iowa State University Press, Ames., Iowa. pp. 143160.

18. Samad MA (2000). An overview of livestock research reports published during the twentieth century in Bangladesh. Bangladesh Veterinary Journal 34: 53-149.

19. Shivachandra SB, Kumar AA, Gautam R, Singh VP, Saxena MK and Srivastava SK (2005). Identification of avian strains of Pasteurella multocida in India by conventional and PCR assays. Veterinary Journal 172: 561-564.

20. Singh R, Remington B, Blackall P and Turni C (2014). Epidemiology of fowl cholera in free range broilers. Avian Diseases 58: 124-128. 